\title{
Attitudes of neurologists, psychiatrists, and psychotherapists towards predictive testing for Huntington's disease in Germany
}

\author{
U Thies, B Bockel, V Bochdalofsky
}

\begin{abstract}
Predictive testing for Huntington's disease (HD) in Germany is performed by genetic counsellors, neurologists, psychiatrists, and psychotherapists. In order to evaluate the attitudes of neurologists, psychiatrists, and psychotherapists in Germany towards predictive testing for HD, a postal questionnaire was sent to this group. Two German Bundesländer were chosen, Baden Württemberg (BW) and Niedersachsen (NS). Of 469 persons interviewed the response rate was $32.6 \%$. The questionnaire consisted of 17 items assessing sociodemographic data, acquaintance with HD patients, lay organisations, attitudes towards genetic counselling, presymptomatic and prenatal DNA testing, and reproduction of persons at risk for $\mathrm{HD}$.

More than $70 \%$ of the subjects were well informed about predictive DNA testing but knowledge about the details of the test procedure, especially the World Federation of Neurology (WFN) and International Huntington Association (IHA) ${ }^{1}$ recommendations, was quite low $(11 \cdot 8 \%)$. Nevertheless, the majority would recommend predictive testing for HD although they anticipated problems for the probands. The majority of our respondents favoured psychological test and post-test counselling for those tested. Concerning reproduction, most subjects favoured prenatal testing or that persons at risk should refrain from having children. We found that the opinions of practitioners and at risk persons differed with respect to the predictive DNA test and, particularly, to prenatal testing. Therefore the testing procedure could be improved if practitioners were better informed about the DNA test in general and about the attitudes and wishes of their patients.

( $\mathcal{F}$ Med Genet 1993;30:1023-7)
\end{abstract}

Institute of Human Genetics, University of Göttingen.

Gosslerstrasse 12D, W-37073 Göttingen, Germany.

U Thies

B Bockel

V Bochdalofsky

Correspondence to Dr Thies.

Received 14 July 1993. Revised version accepted 27 September 1993.

Huntington's disease (HD) is an autosomal dominant, neurodegenerative disease with late onset that results in a progressive movement disorder accompanied by psychiatric alterations and cognitive impairment. It affects 1 in 10000 persons in most European populations. ${ }^{2}$ The onset of HD occurs in or around the fourth decade of life and leads to death within 15 to 20 years. Although the gene has now been identified, the biochemical basis of the disease is not yet understood and there is no effective treatment in delaying or preventing the onset or progression of the disease.

In 1983 Gusella et $a l^{3}$ localised the genetic defect to the tip of the short arm of chromosome 4. After finding close genetic linkage between the G8 probe and the HD gene, predictive molecular testing became available for at risk persons from HD families. Until the identification of the HD gene, which was published in March 1993, ${ }^{4}$ only an indirect approach was available to predict whether or not persons at risk were gene carriers. The error rate of the indirect approach with closely linked polymorphic markers was around $2 \%$.

In Germany there are over 8000 persons affected with HD. Presymptomatic and prenatal testing for at risk persons was started in 1989 at the Institute of Human Genetics, Göttingen. Predictive testing in $\mathrm{HD}$ raises ethical and moral questions. Therefore predictive testing was performed within a structured protocol, as follows. The recommendations for predictive testing published by the International Huntington Association (IHA) and the World Federation of Neurology (WFN) ${ }^{1}$ are part of our test procedure. Furthermore, the cooperation of the proband, genetic counsellor, neurologist, psychiatrist, and psychotherapist is required. For the indirect approach it is essential to have the diagnosis of HD confirmed by at least one neurologist/psychiatrist. Clinical examination of the proband is necessary to exclude early signs of the illness, because the goal of predictive testing is to ascertain the level of risk of developing HD in currently healthy subjects. In probands with serious risk of suicide or other psychiatric symptoms the test is postponed. The test result is only given to the proband if professional support in the test and post-test phase is ensured. The test result is disclosed in a session with the genetic counsellor, the psychotherapist, and the proband when all three parties agree. Up to February 1993 in our Institute 52 indirect predictive and 10 prenatal tests had been performed.

The direct test approach now available will

revolutionise predictive testing in subjects at risk for HD and make it possible in families in which the family structure was unsuitable for indirect testing or where the diagnosis of HD remains uncertain. Nevertheless, the above mentioned problems associated with preclinical testing for a late onset disorder will remain and therefore the current guidelines for testing are also valid for the future.

Whereas a large number of surveys concerning the attitudes of persons at risk towards 
predictive testing have been performed, ${ }^{5-14}$ there have only been a few studies on the attitudes of professionals to presymptomatic testing in HD. ${ }^{1516}$

In the present study we tried to assess the knowledge and attitudes of neurologists, psychiatrists, and psychotherapists in Germany towards predictive DNA testing. The results of the study suggest that knowledge of this group in specific areas needs to be enlarged. Along with genetic counsellors, this group is mainly involved in the test procedure and the decision making process of the probands. Therefore we tried to find out if this group would support at risk persons in the test and post-test phases.

\section{Sample composition and methods SUBJECTS}

Questionnaires were sent to 469 neurologists, psychiatrists, and psychotherapists from Baden Württemberg (BW) (256) and Niedersachsen (NS) (213) listed in the Ärztebuch (medical directory) 1990.

\section{QUESTIONNAIRE}

The questionnaire consisted of 17 questions assessing sociodemographic data, acquaintance with HD patients, lay organisations, knowledge about recent developments in HD research, attitudes towards genetic counselling, presymptomatic and prenatal testing, and reproduction of persons at risk for HD. The questions were closed or open ended (appendix).

The anonymous questionnaire was accompanied by a personal letter giving a minimum of information about prenatal and presymptomatic DNA testing which allowed those who were not well informed about the disorder to answer the questions.

\section{STATISTICAL ANALYSIS}

Using the $\chi^{2}$ test or Fisher's exact test, statistical analyses were carried out with the SAS statistical package. ${ }^{17}$ The Bonferoni multiple testing procedure was used in all cases. In the following sections the values are only mentioned if the results are significant.

\section{Results}

RESPONDENTS

Replies were received from December 1991 to March 1992; 153 questionnaires were returned, 56 from Niedersachsen (return rate $26.3 \%$ ) and 97 from Baden Württemberg (return rate $37.9 \%$ ). The returns were identified by the postmark. No apparent reason exists for the lower return rate from NS. The respondents' qualifications in the different areas of neurology, psychology, and psychotherapy are shown in table 1 . There are no differences in their answers and $127(83 \%)$ stated that they had either counselled or treated at least one patient with $\mathrm{HD}$ (median $2,25 \%$ quantile 1 and $75 \%$ quantile 4 ).
Table 1 Qualification of respondents.

\begin{tabular}{lrr}
\hline Qualification & No & $\%$ \\
\hline Neurologist & 16 & $10 \cdot 5$ \\
Psychiatrist & 1 & $0 \cdot 7$ \\
Psychotherapist & 10 & $6 \cdot 5$ \\
Neurologist/psychiatrist & 65 & $42 \cdot 5$ \\
Neurologist/psychotherapist & 4 & $2 \cdot 6$ \\
Psychiatrist/psychotherapist & 4 & $2 \cdot 6$ \\
Neurologist/psychiatrist/psychotherapist & 51 & $33 \cdot 3$ \\
No information & 2 & $1 \cdot 3$ \\
Total & 153 & 100 \\
\hline
\end{tabular}

Table 2 Circumstances under which the preditive test is recommended (answered by $44 \%$ of the respondents).

Family planning

Sake of partnership

Psychological problems

Personal lifestyle planning

Other reasons (including answers: only after

identification of the gene, only in case of a cure)

Table 3 Anticipated problems of predictive testing (answered by $86 \%$ of the respondents).

Psychological problems

No protection for the privacy of personal data

Problems with social life (friends, etc)

Problems with insurance companies

Family problems

Risk of suicide

Other problems

\section{LAY ORGANISATIONS}

Addresses of lay organisations (Deutsche Huntington Hilfe eV and Deutsche Huntington Gesellschaft $\mathrm{eV}$ ) were only known by 41 respondents $(26.8 \%)$, but $82(53.6 \%)$ would be willing to arrange contact between at risk persons and lay organisations. The willingness to arrange contact was different between Baden Württemberg (46 respondents, $47 \cdot 4 \%$ ) and Niedersachsen (36 respondents, $64 \cdot 3 \%$ ).

KNOWLEDGE ABOUT PREDICTIVE TESTING

A total of 112 respondents $(73 \cdot 2 \%)$ knew that presymptomatic DNA diagnosis is possible, 89 $(58.2 \%)$ knew that for the indirect approach the whole family must be analysed, and 18 $(11.8 \%)$ were familiar with the WFN and IHA recommendations for predictive testing for HD. Eight $(5 \cdot 2 \%)$ respondents stated that they would counsel at risk persons themselves, 106 $(69.3 \%)$ would forward these persons to a genetic counselling unit, and $37(24 \cdot 2 \%)$ would cooperate with a genetic counsellor (not answered $3,1.3 \%$ ). It turned out that knowledge of the details of the test procedure of those who counsel by themselves was insufficient. Sixty-eight $(44 \cdot 4 \%)$ would recommend predictive DNA testing for at risk persons under certain circumstances (table 2), whereas $26(16.9 \%)$ would recommend testing in all cases. One respondent would not recommend testing at all. The answer rate to this question was low because the subjects who chose to refer probands directly to genetic counselling units were not asked to answer this question $(58,37.9 \%)$. Concerning predictive testing and the related problems, which are listed in table 3, $132(86.3 \%)$ physicians anticipated 
Table 4 Opinions about reproduction and prenatal testing in HD.

\begin{tabular}{|c|c|c|c|}
\hline & Yes $(\%)$ & No $(\%)$ & No answer $(\%)$ \\
\hline $\begin{array}{l}\text { "Probands who are given a raised risk of developing } \\
\text { HD should not have children". } \\
\text { "Would you approve of prenatal testing in the case }\end{array}$ & $80 \cdot 4$ & $12 \cdot 4$ & $7 \cdot 2$ \\
\hline $\begin{array}{l}\text { of a pregnancy of an at risk person?" } \\
\text { (BW + NS) } \\
\text { NS }(56) \\
\text { BW }(97)\end{array}$ & $\begin{array}{l}88 \cdot 9 \\
49(87 \cdot 5) \\
85(87 \cdot 6)\end{array}$ & $\begin{array}{l}7 \cdot 2 \\
5(8 \cdot 9) \\
6(6 \cdot 2)\end{array}$ & $\begin{array}{l}3 \cdot 9 \\
2(3 \cdot 6) \\
6(6 \cdot 2)\end{array}$ \\
\hline
\end{tabular}

problems whereas $11(7 \cdot 2 \%)$ did not (not answered $10,6.5 \%$ ).

TEST PROCEDURE

Psychotherapeutic support for persons at risk who want predictive testing was favoured by the majority of the respondents and about $94.8 \%(145)$ of the subjects favoured post-test counselling. However, $82(53.9 \%)$ were of the opinion that it is only necessary in cases of a raised risk, whereas $60(39.2 \%)$ thought that post-test counselling should take place irrespective of the test result. Two $(1.3 \%)$ respondents considered post-test counselling unnecessary (not answered 9, 5.9\%).

\section{REPRODUCTION AND PRENATAL TESTING IN PERSONS AT RISK}

Concerning reproduction and prenatal testing (table 4), $123(80.4 \%)$ respondents thought that persons at risk should refrain from having children of their own (not answered 11, 7.2\%). The majority $(136,88.9 \%)$ was in favour of prenatal DNA testing if one parent is an HD gene carrier, whereas $11(7 \cdot 2 \%)$ rejected prenatal molecular testing (not answered 6, $3.9 \%$ ). A total of $35.9 \%$ (55) would tolerate an abortion only in those at $98 \%$ risk, another $51 \%$ (78) would justify it at $50 \%$ risk, and $9.8 \%(15)$ would refuse an abortion at all (no answer $5,3 \cdot 3 \%$ ).

\section{Discussion}

Predictive testing in HD raises ethical, legal, social, and psychological questions, which are well known by neurologists, psychiatrists, and psychotherapists. Our survey showed that they are aware that genetic testing for this late onset, incurable disease needs special support and counselling for at risk persons.

In general it turned out that the respondents are well informed about predictive testing and DNA analysis in HD. Most of the physicians know about the possibility of DNA testing in HD $(73.2 \%)$. This rate is higher than in previous studies; for example, only $24 \%$ of Scottish practitioners were familiar with the test. ${ }^{15}$ However, the Scottish study was performed two years ago and practitioners are now, in general, better informed about DNA testing. A Dutch study performed in $1992^{16}$ showed that $59 \%$ of general practitioners (GPs) who had persons at risk as patients were familiar with the test. However, details of the test procedure were not well known by our respondents; $58.2 \%$ of the physicians knew that predictive testing at the time was only possible by family study (indirect approach). Only a few
$(11.8 \%)$ were aware of the international guidelines of the IHA and WFN. ${ }^{1}$ This might explain the general willingness of the respondents to cooperate with a genetic counselling unit instead of counselling HD persons by themselves. However, the knowledge of the eight physicians who would not cooperate with genetic counselling units was less than the other respondents. We think that genetic counselling and especially DNA testing counselling should remain the responsibility of genetic counselling units.

The main reasons given by the respondents for recommending predictive testing to at risk persons were family planning, the sake of partnership, and psychological reasons. At risk persons would take the test mainly because they want more certainty about their carrier status ${ }^{101318}$; 'family planning', for example, has a lower priority in their opinion. Furthermore, the number of at risk persons opting to take part in the test procedure is lower ${ }^{19}$ than the recommendations of professionals to take part in the test procedure. This shows that the decisions of at risk persons are not always influenced by their physicians. The different ranking of the reasons for taking part in the test might result from the more general view of practitioners and from the fact that they are not personally involved. The difference in the attitudes of physicians and at risk persons is even more pronounced regarding the problems which may arise during or as a consequence of the test procedure. Most respondents (more than $86 \%$ ) believe that many problems might arise, such as risk of suicide, psychological and social problems, problems with insurance companies, and lack of confidentiality. Most at risk persons do not rank psychological problems or the risk of suicide highly, ${ }^{6}$ whereas the other problems do rank highly in their opinion. The physicians seem to be well aware of the fact that persons who received raised risks were more shocked than they themselves had expected. ${ }^{2021}$

Willingness of the respondents to give support after disclosing the test result was not as great as expected $(40 \%)$. The majority $(54 \%)$ thought that it was only necessary in the case of an increased risk. In fact, even persons with a decreased risk have great difficulty in coping with this information and need professional support, as the surveys of Tibben et $a l^{22}$ and Huggins $e t a l^{3}$ indicated.

There is an opinion contained in German textbooks for neurologists ${ }^{24}$ that persons at risk for HD should refrain from having children and about $80 \%$ of our respondents would agree with this. Only a few of them believe that the decision whether to have children should be left completely to the persons at risk and their partners. These answers suggest that the physicians want to eradicate the disease.

About $90 \%$ of our respondents, the same rate as in the Dutch study, approved of prenatal testing for HD and termination of a high risk pregnancy. In opposition to that finding, only $29.4 \%$ of at risk persons would use prenatal testing, as shown in the Vancouver study. ${ }^{9}$ In the Dutch study ${ }^{14}$ the number of at 
risk persons who would take part in prenatal testing is larger (about $60 \%$ ) than in Canada but not as high as the professionals.

In our results, we expected a difference between the predominantly Catholic Bundesland BW and the more Protestant NS in the answers concerning abortion, but interestingly we could not find any. Objection to prenatal testing may be based on opposition to terminating a high risk pregnancy for a late onset disorder in general, rather than on any religious aspects.

A difference between the two Bundesländern was found in the willingness of physicians to pass addresses of lay organisations on to their patients. Whereas in NS around $65 \%$ would recommend lay organisations to the patients, in BW the level was only $47 \%$, although the number of practitioners who knew about a special organisation was equal in both regions $(26 \cdot 8 \%)$. This appears to represent a real difference between the physicians, which we could not explain, as the lay organisations act in a similar way in both Bundesländern. However, the mean level of willingness of practitioners to cooperate with lay organisations for $\mathrm{HD}$ is equal to that for other diseases $(63 \%$ alcoholism, $48 \%$ cancer, etc). ${ }^{25}$

Isolating or mapping of genes causing hereditary diseases will provide the opportunity to test an increasing number of subjects at risk. Knowledge about DNA testing is not restricted to genetic counsellors as our study showed. Although HD is a relatively rare condition the physicians questioned were, in general, well informed about molecular testing, but had less specific knowledge. The test procedure and support for at risk persons could be improved if it is acknowledged that the opinions and attitudes of professionals and at risk subjects are sometimes quite different. Another area for improvement will be to keep practitioners well informed about recent developments in DNA testing by the genetic counselling units in order to guarantee the best information for the probands.

The authors are grateful to all the neurologists, psychiatrists, and psychotherapists who took part in this study. We thank PD Dr M Dose for helpful discussion concerning the questionnaire. We also thank Professor W Engel for advice and helpful discussion, A Czarny for secreterial help, and D Murphy for reading the manuscript.

1 World Federation of Neurology Research Committee. Research Group on Huntington's disease. Ethical issues policy statement on Huntington's disease molecular genetics predictive test. $\mathcal{F}$ Neurol Sci 1989;94:327-32 and $\mathcal{F}$ Med Genet 1990;27:34-8.

2 Harper PS. Huntington's disease. London: Saunders, 1991.

Gusella JF, Wexler NS, Conneally PM, et al. A polymorphic DNA marker genetically linked to Huntington's disease. Nature 1983;306:234-8.

4 The Huntington's Disease Collaborative Research Group. A novel gene containing a trinucleotide repeat that is expanded and unstable on Huntington's disease chromosomes. Cell 1993;72:971-83.

5 Mastromauro C, Myers RH, Berkman B. Attitudes toward presymptomatic testing in Huntington disease. $A m \mathcal{F} \mathrm{Med}$ Genet 1987;26:271-82.

6 Kessler S, Field T, Worth L, Mosbarger H. Attitudes of persons at risk for Huntington disease toward predictive testing. Am 7 Med Genet 1987;26:259-70.

7 Markel DS, Young AB, Penney JB. At-risk persons attitudes toward presymptomatic and prenatal testing of Huntington disease in Michigan. Am $f$ Med Genet 1987;26:295-305.

8 Meissen GJ, Berchek RL. Intended use of predictive testing by those at risk for Huntington disease. Am $\mathcal{F}$ Med Genet 1987;26:283-93.

9 Bloch M, Fahy M, Fox S, Hayden MR. Predictive testing for Huntington disease. II. Demographic characteristics, life-style patterns, attitudes and psychosocial assessments of the first fifty-one test candidates. Am $\mathcal{J}$ Med Genet 1989;32:217-24.

10 Evers-Kiebooms G, Cassiman JJ, Van den Berghe $H$. Attitudes towards predictive testing in Huntington's disease: a recent survey in Belgium. $f$ Med Genet 1987;24:275-9.

11 Wolff $G$, Walter W. Attitudes of at-risk persons for Huntington disease toward predictive genetic testing. Birth Defects 1992;28:119-26.

12 Quaid KA, Brandt J, Faden RR, Folstein SE. Knowledge, attitude and the decision to be tested for Huntington's disease. Clin Genet 1989;36:331-8.

13 Meissen GJ, Mastromauro C, Kiely DK, McNamara DS, Myers RH. Understanding the decision to take the predictive test for Huntington disease. Am $\mathcal{f}$ Med Genet 1991;39:404-10.

14 Tibben A, Frets PG, van de Kamp JJP, et al. Presymptomatic DNA testing for Huntington disease: pretest attitudes and expectations of applicants and their partners in the Dutch program. Am 7 Hum Genet 1993;48:10-16.

15 Mennie ME, Holloway SM, Brock DJ. Attitudes of general practitioners to presymptomatic testing for Huntington's disease. $\mathcal{f}$ Med Genet 1990;27:224-7.

16 Thomassen R, Tibben A, Niermeijer MF, van der Does E, van de Kamp JJP, Verhage F. Attitudes of Dutch general practitioners towards presymptomatic DNA-testing for practitioners towards presymptomatic DNA-

17 SAS Institute Inc. SAS $/ S T A T^{T M}$ User's Guide. Release 6.03 edition. Cary, NC: SAS Institute Inc, 1988.

18 Fox S, Bloch M, Fahy, Hayden MR. Predictive testing for Huntington disease. I. Description of a pilot project in British Columbia. Am f Med Genet. 1989;32:211-16.

19 Craufurd D, Dodge A, Kerzin-Storrar L, Harris R. Uptake of presymptomatic predictive testing for Huntington's disease: Lancet 1989;ii:603-5.

20 Bloch M, Adams S, Wiggins S, Huggins M, Hayden MR. Predictive testing for Huntington disease in Canada: the experience of those receiving an increased risk. $A m \mathcal{F} M e d$ Genet 1992;42:499-507.

21 Tyler A, Morris M, Lazarou L, Meredith L, Myring J, Harper PS. Presymptomatic testing for Huntington's disease in Wales. Br $\mathcal{F}$ Psychiatry 1992;161:481-8.

22 Tibben A, Vegter van de Vlis M, Skraastaad MI, et al. DNA testing for Huntington's disease in the Netherlands; a retrospective study on psychosocial effects. $\mathrm{Am} \mathcal{J} \mathrm{Med}$ Genet 1992;44:94-5.

23 Huggins $M$, Bloch $M$, Wiggins $S$, et al. Predictive testing for Huntington disease in Canada. Adverse effects and unexpected results in those receiving a decreased risk. $\mathrm{Am}$ unex Genet 1992;42:508-15.

24 Tölle R. Psychiatrie. Berlin: Springer Verlag, 1991

24 Tölle R. Psychiatrie. Berlin: Springer Verlag, 1991. Kooperation von Ärzten mit Selbsthilfegruppen zur Kooperation von Arzten mit Selbsthilfegruppen zur
Effektivitätsverbesserung der ambulanten Versorgung. In: Zusammenarbeit von Ärzten und Selbsthilfegruppen. Zentralinstitut für die kassenärztliche Versorgung. Köln, Deutscher Ârzteverlag, 1990; 99-102. 
Appendix Questionnaire.

(1) Are you a practising

Are you a practising
Neurologist Psychiatrist Psychotherapist
Private practice

Doctor in a university hospital

Doctor in a district hospital

Doctor in a psychiatric hospital

(2) Have you counselled patients with HD?

Yes (number) No

(3a) Are you familiar with HD lay organisations?

(3b) Do you know addresses of lay organisations and would you make contact with them?

Yo you know addresses of

(4) Were you aware of the possibility of DNA diagnosis for HD?

(5) Are you aware that DNA diagnosis is only possible within a family investigation?

(5) Are you aware that DNA diagn

(6) If an at risk person wishes to have presymptomatic DNA testing carried out, would you: Counsel them yourself?

Send them to a genetic counselling unit?

(7) If you carry out the counselling yourself:

Would you recommend presymptomatic DNA diagnosis to persons at risk for HD?

No

I would recommend DNA diagnosis only in particular circumstances, which are:

If the person wishes to have children

If risk modification is important for the partnership

If risk modification seems to be important for physical reasons

For professional reasons

For the following reasons:

For the following reasons:

Only when a cure becomes available
Only when, once the gene has been identified, investigation of at risk patients is possible without reference to other family members

(8) Do you believe that, as a result of participation in presymptomatic DNA testing, problems could arise which would

require special attention?

If yes, which problems do you believe would arise?

Negative influence on the family

Negative psychological effect on the patient

Increased risk of suicide

Negative social reaction (loss of job, stigma of being 'sick', etc)

Problems with health and life insurance

No protection of the privacy of personal data

Other problems

(9) Are you acquainted with the WFN (World Federation of Neurology) and IHA (International Huntington $A$ ssociation)

recommendations concerning DNA diagnosis for HD (see $\mathcal{F}$ Neurol Sci 1989;94:327-32)
Yes

(10) DNA diagnosis should only be carried out in laboratories which work in cooperation with a genetic counselling unit and with the neurologist/psychiatrist/psychotherapist

and with the neurologist/psych

DNA diagnosis could also be

Yes diagnosis could also be

(11) Should at risk persons who are taking part in a DNA diagnosis programme receive counselling from a

neurologist/psychotherapist/psychiatrist with regard to the test results

Yes No

(12) Should the appointment for the test result be set by the supervising doctor?
Yes

(13) The test result should only be given to the patient in the presence of the supervising doctor (neurologist/psychiatrist/psychotherapist) and the genetic counsellor

(14) After receiving the test result, should the proband be looked after by the supervising doctor? Only if the proband receives a high risk

In every case

No

(15) Do you believe that probands who receive a high risk should abstain from having children?

(16) One parent carries the gene for HD. Every child has a risk of $50 \%$. In case of a pregnancy the risk can be more accurately determined by molecular diagnosis $(2 \%$ or $98 \%)$. Do you think prenatal diagnosis is justified in this case? Yes No

(17) Do you think an abortion is justifiable?

In the case of a $50 \%$ risk

In the case of a $98 \%$ risk

No 